\title{
Application of a Lateral Flow Immunoassay to Determine Ampicillin Residues in Muscle Tissue of Olive Flounder (Paralichthys olivaceus)
}

\author{
Chun Nam Cha', Eun-Ah Yu², Min Jung Shin ${ }^{3}$, Eun Kee Park ${ }^{4}$, Hyunju Choi ${ }^{5}$, Suk Kim, and Hu Jang Lee* \\ Research Institute of Life Sciences, College of Veterinary Medicine, Gyeongsang National University, Chinju 660-701, Korea \\ ${ }^{1}$ Engineering Research Institute, Department of Industrial Systems Engineering, Gyeongsang National University, \\ 900 Gajwa-dong, Chinju 600-701, Korea \\ ${ }^{2}$ Tongyeong National Quarantine Station, Ministry of Health \& Welfare, Tongyeong 650-110, Korea \\ ${ }^{3} 3 \mathrm{M}$ Health Care Business Group Laboratory, 3M Korea, Hwaseong 445-170, Korea \\ ${ }^{4}$ Department of Medical Humanities and Social Medicine, College of Medicine, Kosin University, Busan 602-703, Korea \\ ${ }^{5}$ Elderly Life Redesign Institute, Department of Biomedical Laboratory Science, Inje University, Gimhae 621-749, Korea \\ (Received May 23, 2013/Revised June 8, 2013/Accepted June 12, 2013)
}

\begin{abstract}
Antibiotic Detection Kit (Combination I), a lateral flow immunoassay (LFIA) developed for the detection of antibiotic residues in milk, was utilized for the analysis of antibiotic residues in the muscle tissue of olive flounder. After 60-min treatment by dipping in water dosed with ampicillin (200-g/ton water), the residue depletion of ampicillin was investigated in 25 cultured olive flounder (Paralichthys olivaceus). Muscles of fish were sampled on the $1 \mathrm{st}, 2 \mathrm{nd}, 3 \mathrm{rd}$, 4th and 5th day after drug treatment. The concentration of ampicillin in the muscle was determined by LFIA. The absorbance ratio of the sample to the control blank (Bs/Bo) was employed as an index to determine the muscle residues in olive flounder. To investigate the recovery rate, standard solutions were added to muscle samples to give final concentrations in the muscle of 4 and $8 \mathrm{ng} / \mathrm{ml}$. The recovery rates of all spiked samples were $>96 \%$ of the spiked value. Ampicillin was detected in the muscle of fish treated with the drug until the 2nd day of the withdrawal period. The present study showed that the LFIA can be easily adopted to predict ampicillin residues in tissue of farmed fishes.
\end{abstract}

Key words: lateral flow immunoassay, ampicillin, muscle residue, olive flounder

\section{Introduction}

Recently, aquaculture continues to be the fastest growing animal food producing sector, and aquaculture accounts for $46 \%$ of the total food fish supply ${ }^{1)}$. As is the case with terrestrial animal production, antibacterials are also used in aquaculture in an attempts to control bacterial disease $\mathrm{e}^{2,3)}$.

Ampicillin is a beta-lactam antibiotic, a semi-synthetic penicillin that has been used extensively to treat bacterial diseases caused by gram-positive and gram-negative bacteria, and controlled since $1961^{4,5)}$. In some people, ampicillin, like its congeners, may result in severe hypersensitivity reactions ${ }^{6}$. As the ingestion of ampicillin as a residue in seafood is of public health interest, since September 2007, the Korean Food and Drug Administration (FDA) has set a tolerance level of $0.05 \mathrm{mg} / \mathrm{kg}$ in farmed fish and seafood ${ }^{7)}$.

\footnotetext{
*Correspondence to: Hu Jang Lee, Research Institute of Life Sciences, College of Veterinary Medicine, Gyeongsang National University, Chinju 660-701, Korea

Tel: 82-55-772-2352, Fax: 82-55-772-2308

E-mail: hujang@gnu.ac.kr
}

Excessive use of antibiotics such as ampicillin has led to a wide emergence of antibiotic-resistant bacteria ${ }^{8)}$. To prevent the emergence of antibiotic-resistant bacteria, unnecessary dosing of antibiotics should be minimized and the use of antibiotics in fish farming should be tightened by monitoring antibiotic residues in different biological samples ${ }^{9}$.

There are traditional approaches for the detection of ampicillin residues such as microbial inhibition tests, immunoassays and chromatographic methods. Widely used microbial inhibition methods are relatively complicated, time-consuming and non-specific to ampicillin ${ }^{10)}$. On the other hand, chromatographic methods, such as high-performance liquid chromatography (HPLC), have a sensitivity and specificity for the analysis of antibiotic residues. However, chromatographic methods are unsuitable for analyzing large numbers of samples because of certain disadvantages such as high price, requirement of special equipment, and sample extraction protocols requiring expert personnel ${ }^{11)}$.

Various immunoassay methods have been developed and adopted for the detection of antibiotic residues in animal and fish products. Immunoassays have been popularly used for the detection of antibiotic residues in food due to their 
(A)

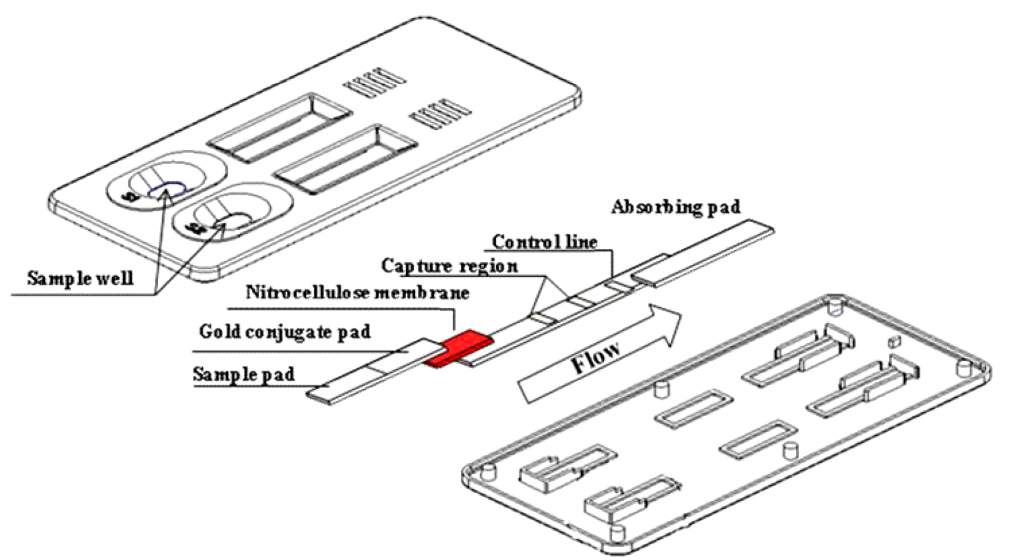

(B)

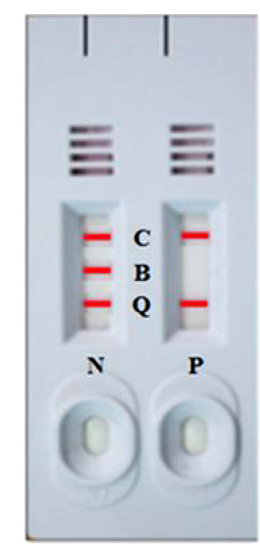

Fig. 1. Schematic diagram (A) and photograph of the representative results of LFIA (B). C, control; B, $\beta$-lactam antibiotics; Q, quinolone antibiotics; $N$, negative for $\beta$-lactam antibiotics; $P$, positive for $\beta$-lactam antibiotics.

simplicity and ability to screen large numbers of samples ${ }^{12,13)}$.

LFIAs are simple devices used to detect analytes in a sample and are often produced in a dipstick format. The test sample is dispensed into the sample well of the kit and flows along a solid substrate by capillary action ${ }^{14)}$. After the sample has been applied to the test, it encounters a colored reagent that mixes with the sample and moves the substrate, encountering lines that have been pretreated with an antibody. Depending on the analytes present in the sample, the colored reagent can become bound at the test line ${ }^{15)}$. Fig. 1 represents the schematic diagram and photograph of representative results of a lateral flow immunoassay (LFIA).

In the present study, LFIA was utilized for the detection of ampicillin in the muscle of a farmed fish, olive flounder.

\section{Materials and Methods}

\section{Regents and immunoassay kit}

Ampicillin was purchased from Sigma-Aldrich Korea (Yongin, Korea). Aqua-Ampi powder (100 g (ampicillin sodium $100 \mathrm{~g}$ (activity))/kg, withdrawal period, 7-days) was obtained from Dae Han New Pharm Co. Ltd. (Seoul, Korea). Antibiotic Detection Kit (Combination I) was kindly supplied by $3 \mathrm{M}$ Korea (Seoul, Korea).

\section{Drug treatment and collection of samples}

The fish used in this study were 25 healthy olive flounders (Paralichthys olivaceus) weighting an average of $270 \pm 26 \mathrm{~g}$ with no previous history of antibiotic treatment. After for 7 days, twenty-five olive flounders were treated by dipping in water dosed with ampicillin (200 g/ton) for $60 \mathrm{~min}$. Muscles were sampled from each of five fish on the 1st, 2nd, 3rd, 4th, and 5th day after drug administration.

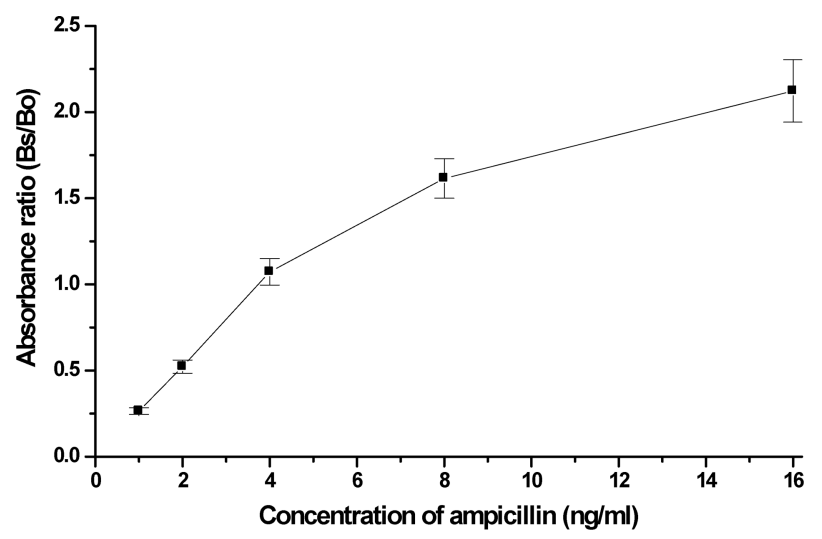

Fig. 2. Standard curve of ampicillin in muscle of olive flounder. Detection limit of ampicillin was calculated as $4 \mathrm{ng} / \mathrm{g}$. Absorbance ratio obtained with blank tissue (Bo) and with muscle tissue spiked with ampicillin (Bs).

\section{Analysis of ampicillin residues}

According to the manufacturer's protocol, residual ampicillin was extracted from muscle samples. One gram of ground muscle from each olive flounder was weighed in a 50 -ml tube and $5 \mathrm{ml}$ of 10-time-diluted extraction buffer was added, and the contents were vigorously mixed for $3 \mathrm{~min}$ in a vortex mixer. After centrifugation for $10 \mathrm{~min}$ at $30,000 \times$ g, $120 \mu \mathrm{l}$ of the supernatant was dispensed into the sample well of the immunoassay kit and incubated on a heating block at $45^{\circ} \mathrm{C}$ for $10 \mathrm{~min}$. After incubation, the kit was inserted into the absorbance reader. From the absorbance ratio (Bs/Bo, Bs, sample absorbance, Bo, control absorbance), the level of ampicillin residue in the sample was obtained using a standard curve of ampicillin.

\section{Preparation of standard curve}

The standard curve of ampicillin was constructed to deter- 
mine the detection limit of the drug. A stock solution of $100 \mu \mathrm{g} / \mathrm{ml}$ of ampicillin was prepared and stored at $-20^{\circ} \mathrm{C}$. This standard solution was used for the preparation of both calibration solutions and fortified samples. Just before use, the stock solution was diluted in muscle extracts from non-treated fish, to prepare $1,2,4,8$ and $16 \mathrm{ng} / \mathrm{ml}$ working standard solutions.

\section{Recovery test}

To obtain the recovery rate, the standard solutions were added to muscle samples to give final concentrations in the muscle of 4 and $8 \mathrm{ng} / \mathrm{ml}$. After blending, these samples were extracted as described above and then analyzed in a blind fashion.

\section{Results}

The standard curve of ampicillin was constructed to determine the detection limit of the drug. As shown in Fig. 1, the detection limit of ampicillin was less than $4 \mathrm{ng} / \mathrm{ml}$ based on the Bs/Bo ratio of 1.0 in the assay system. The standard curve of ampicillin showed linear regression between 1 and $8 \mathrm{ng} / \mathrm{ml}\left(R^{2}=0.972\right)$. In a previous study ${ }^{9}$, ampicillin residue in the muscle tissue of olive flounder was determined using a solid-phase fluorescence immunoassay and the detection limit of ampicillin was less than $5 \mathrm{ng} / \mathrm{ml}$ based on the Bs/Bo ratio. Furthermore, the ampicillin standard curve showed linear regression between 5 and $50 \mathrm{ng} / \mathrm{ml}\left(R^{2}=\right.$ 0.996). Douglas et al. carried out the validation of a $\beta$ lactam and flunixin rapid lateral flow test in raw milk, and the detection limit of ampicillin was $6.8 \mathrm{ng} / \mathrm{ml}^{15}$.

In the present study, the detection limit of ampicillin was similar to the study of Jung et al. ${ }^{9)}$ and slightly higher than that of Douglas et al. $^{15)}$.

Recovery of 4 and $8 \mathrm{ng} / \mathrm{ml}$ of ampicillin from spiked, nontreated muscle is shown in Table 1. All recoveries were greater than $96 \%$ of the spiked value.

Jung et $a l^{9)}$ reported that that recovery rate of 10 and $50 \mathrm{ng} / \mathrm{ml}$ of ampicillin from the spiked muscle of olive flounder was 93.4 and $91.4 \%$, respectively. Han and $\mathrm{Ko}^{16)}$ investigated recovery rates using high-performance liquid chromatography (HPLC) after spiking muscle tissues with ampicillin at concentrations of 0.1 and $1.0 \mu \mathrm{g} / \mathrm{ml}$. The recovery rate for ampicillin was greater than $91 \%$. In addition, Wenhong et $a l .{ }^{17)}$ reported that the recovery rates of ampicillin from catfish muscle fortified at 5, 10 and $20 \mathrm{ng} / \mathrm{g}$ levels, ranged from 89.9 to $95.2 \%$. Considering the kind of samples, the flounder muscle residue concentrations of ampicillin in the present study were similar or slightly higher than those from the studies described above. It was assumed that the different results for recovery rates were due to the experimental
Table 1. Recovery of tetracyclines in muscle of olive flounder using a Solid-phase Fluorescence Immunoassay

\begin{tabular}{ccc}
\hline $\begin{array}{c}\text { Spiked concentration } \\
(\mathrm{ng} / \mathrm{g})\end{array}$ & Bs/Bo ratio ${ }^{1)}$ & Recovery $(\%)^{2)}$ \\
\hline 4 & $1.121 \pm 0.030$ & 105.5 \\
8 & $1.653 \pm 0.026$ & 96.1 \\
\hline
\end{tabular}

Values are expressed as mean \pm SD.

${ }^{1)} \mathrm{Bs} / \mathrm{Bo}$ ratio was calculated as the absorbance of muscle spiked with ampicillin (Bs)/the absorbance of blank (Bo).

${ }^{2)}$ Recovery obtained from the formula, (concentration from the spiked muscle/concentration of the spiked standard solution) $\times 100$.

Table 2. Depletion profiles of ampicillin in flounder muscle during the withdrawal period

\begin{tabular}{cccc}
\hline $\begin{array}{c}\text { Withdrawal } \\
\text { (days) }\end{array}$ & $\begin{array}{c}\text { No of } \\
\text { positive results }\end{array}$ & Bs/Bo ratio & $\begin{array}{c}\text { Concentration } \\
(\mathrm{ng} / \mathrm{g})\end{array}$ \\
\hline 1 & 5 & $2.271 \pm 0.083$ & $22.62 \pm 0.92$ \\
2 & 3 & $0.814 \pm 0.152$ & $2.93 \pm 0.68$ \\
3 & 0 & $0.467 \pm 0.061$ & $1.87 \pm 0.24$ \\
4 & 0 & $0.295 \pm 0.027$ & $1.08 \pm 0.11$ \\
5 & 0 & $<0.200$ & $<0.50$ \\
\hline
\end{tabular}

Values are expressed as mean $\pm \mathrm{SD}$.

${ }^{11} \mathrm{Bs} / \mathrm{Bo}$ ratio was calculated as the absorbance of muscle spiked with ampicillin (Bs)/the absorbance of blank (Bo).

conditions and methods of sample extraction.

The analytical results of ampicillin in olive flounder muscle are shown in Table 2. On the 1st day after drug treatment, all muscle samples showed positive results $(\mathrm{Bs} / \mathrm{Bo}$ ratio $>1.0$ ). After the 3 rd day of withdrawal, all muscle samples showed a negative reaction $(\mathrm{Bs} / \mathrm{Bo}$ ratio $<1.0)$, and were believed to decrease under $4.0 \mathrm{ng} / \mathrm{ml}$.

In the research by Cho et al. ${ }^{18)}$, muscle samples from olive flounders orally treated with ampicillin $(100 \mathrm{mg} / \mathrm{kg}$ body weight) for 5 consecutive days were analyzed at the residue level of the drug using a HPLC system, and the concentration of ampicillin in muscle was $52 \mathrm{ng} / \mathrm{g}$ on the $2 \mathrm{nd}$ day after drug treatment. Son et al. ${ }^{19)}$ investigated ampicillin residue in the muscles of olive flounder after oral treatment at a dose of $40 \mathrm{mg} / \mathrm{kg}$ body weight for 5 consecutive days, and ampicillin concentration analyzed by HPLC was $23 \mathrm{ng} / \mathrm{g}$ on the $3 \mathrm{rd}$ day. Considering the dosage, treatment period and administration route, the flounder muscle residue concentrations of ampicillin in the present study were similar or slightly lower than those of the studies described above.

According to the results of this study, LFIA can be adopted easily to screen for ampicillin residue in the muscle tissue of farmed fishes after minimal sample preparation. It is suggested that LFIA may be applied to screen for ampicillin in the tissue of fishes on fish farms. If the inspected fishes show positive results, these could be banned from shipping until retest results come back negative, and then they can be shipped. 


\section{Acknowledgments}

This work was supported by 3M Korea Ltd. (Seoul, Korea).

\section{References}

1. Food and Agricultural Organization (FAO): The state of world fisheries and aquaculture 2010. FAO, Rome, pp. 3-5 (2010).

2. Burka, J. F., Hammell, K. L., Horsberg, T. E., Johnson, G. R., Rainnie, D. J. and Speare, D. J.: Drugs in salmonid aquaculture - A review. J. Vet. Pharmacol. Therap. 20, 333-349 (1997).

3. Defoirdt, T., Sorgeloos, P. and Bossier, P.: Alternatives to antibiotics for the control of bacterial disease in aquaculture. Curr. Opin. Microbiol. 14, 251-258 (2011).

4. Rao, C. H. R., Arunkumar, L. C. and Sambasivarao, K. R. S.: Qualitative and quantitative analysis of ampicillin in milk and dairy products. Int. J. Sci. Innova. Dis. 1, 186-191 (2011).

5. Lambert, H. P. and O'Grady, F. W.: Antibiotic and chemotherapy. In: Veterinary medicine. 6th Ed. Churchill Livingstone, New York, pp. 130-139 (1992).

6. Huber, W.G.: Antibacterial drug effectiveness against mastitis pathogens. J. Am. Vet. Med. Assoc. 170, 1182-1184 (1977).

7. Korea Food and Drug Administration (KFDA): Partial revision of criteria and standards for foods. Notification No. 2007-63, KFDA, Seoul, pp. 5-6 (2007).

8. Gundula A.: Ampicillin threat leads to wider transgene concern. Nature 435, 561 (2005).

9. Jung, W. C., Ha, J. Y., Chung, H. S., Heo, S. H., Kim, S. and Lee, H. J.: Application of a solid-phase fluorescence immunoassay to determine ampicillin residues in muscle tissue of olive flounder (Paralichthys olivaceus). Korean J. Vet. Res. 46, 291-294 (2006).

10. Messer, J. W., Leslie, J. E., Houghtby, G. A., Peeler, J. T. and Barnett, J. E. Bacillus stearothermophilus disc assay for detection of inhibitors in milk: collaborative study. $J A O A C$ 65, 1208-1214 (1982).

11. Coyne, R., Bergh, O. and Samuelsen, O. B.: One-step liquid chromatographic method for the determination of oxytetracycline in fish muscle. J. Chromatogr. B 810, 325-328 (2004).

12. Lee, H.J., Lee, M.H. and Han, In K.: Application of ELISA for the detection of penicillin antibiotic residues in live animal. Asian-Aust. J. Anim. Sci. 13, 1604-1608 (2003).

13. Mitchell, J. M., Griffiths, M. W., McEwen, S. A., McNab W. B. and Yee A. J.: Antimicrobial drug residues in milk and meat: causes, concerns, prevalence, regulations, tests, and test performance. J. Food Prot. 61, 742-756 (1998).

14. Peruski, A. H. and Peruski, L. F. Immunological methods for detection and identification of infectious disease and biological warfare agents. Clin. Dign. Lab. Immunol. 10, 506-513 (2003).

15. Douglas, D., Banaszewski, K., Juskelis, R., Al-Taher, F., Chen, Y., Cappozzo, J., McRobbie, L. and Salter, R.S.: Validation of a rapid lateral flow test for the simultaneous determination of $\beta$-lactam drugs and flunixin in raw milk. J. Food Prot. 75, 1270-1277 (2012).

16. Han, K. O. and Ko, I. S.: Determination of ampicillin in $\beta$-lactam antibiotic preparation by means of high performance liquid chromatography. Bull. K. H. Pharma. Sci. 13, 73-76 (1985).

17. Wenhong, L., Catharina, Y. W. A., Harold, C. T.: Rapid method for the determination of ampicillin residues in animal muscle tissues by high-performance liquid chromatography with fluorescence detection. J. Chromatogr. B 694, 401-407 (1999).

18. Cho, Y. H., Jung, W. C., Shin, Y. W., Kim, K. W., Ha, J. Y., Heo, S. H., Kim, E. G., Chung, H. S., Kang, S. J., Choi, Y. J., Kim, S. and Lee, H. J.: Muscle tissue distribution level of ampicillin in olive flounder (Paralichthys olivaceus), rockfish (Sebastes schlegeli), and red sea bream (Pagrus major) following oral administration. J. Vet. Clin. 23, 164-168 (2006).

19. Son, K. T., Jo, M. R., Oh, E. G., Mok, J. S., Kwon, J., Lee, T. S., Song, K. C., Kim, P. H. and Lee, H. J.: Residues of ampicillin and amoxicillin in olive flounder (Paralichthys olivaceus) following oral administration. Kor. J. Fish Aquat. Sci. 44, 464-469 (2011). 